\title{
The Relationship between, Psychological Well-Being and Occupational Self-Efficacy among Teachers in the City of Mysore, India
}

\author{
Fatemeh Salimirad $^{1 *}$, N. L. Srimathi ${ }^{2}$
}

\section{ABSTRACT}

This study aimed at exploring the relationship between Occupational Self-Efficacy and psychological well-being among teachers in the city of Mysore, India. There are two major objectives of the study: to study the relationship between occupational self-efficacy and psychological well-being; and to investigate the effect of the variable of gender on occupational self-efficacy and psychological well-being. 600 teachers, from both Government and Private Schools, have been drowned by random sampling. A Spearman's Correlation Coefficient and Mann Whitney's U test have been applied to analyze hypotheses using SPSS version 20. The results of Spearman's Correlation Coefficient indicated a positive and significant correlation between occupational self-efficacy and psychological well-being. The findings highlighted that, in the educational field, organizations should concentrate on teachers as a key element of the educated society; hence, they should concentrate on the psychological aspects of teachers' personality. The study has also found that high self-efficacy and high psychological well-being are positively related; which in turn, could be considered in workplace in order to progress the productivity of educational outcomes. Finally, there was no significant effect of gender on both occupational self-efficacy and psychological well-being.

Keywords: Occupational Self-Efficacy, Psychological Well-Being, Teachers

Though teachers play a very important role in the success of teaching procedures, their psychological well-being and occupational self-efficacy can affect the efficiency of their teaching methods used in the teaching setting. Accordingly, it is worthy to examine each factor that may affect instructors' psychological well-being and occupational self-efficacy in the course of training to apply efficient methods that let students have better learning proficiency.

Psychological well-being is defined as a state that emerges from feeling of satisfaction with one's physical health, oneself as a person, and with one's close inter-personal relationships. Ryff

\footnotetext{
${ }^{1}$ Research Scholar, University of Mysore, Psychology Department, Mysore, India

${ }^{2}$ Professor, University of Mysore, Psychology Department, Mysore, India

*Responding Author

(C) 2016 I F Salimirad, N Srimathi; licensee IJIP. This is an Open Access Research distributed under the terms of the Creative Commons Attribution License (http://creativecommons.org/licenses/by/2.0), which permits unrestricted use, distribution, and reproduction in any Medium, provided the original work is properly cited.
} 


\section{The Relationship between, Psychological Well-Being and Occupational Self-Efficacy among Teachers in the City of Mysore, India}

and Keyes (1995) consider well-being as a six key dimension issue. These dimensions are (a) self acceptance (b) personal growth (c) having positive intimate and valued relations with others (d) autonomy (e) environment mastery; and (f) finding purpose in life by having goals(salami,2010). In recent decades, Psychological well-being has being had more consideration by many research scholars (Diener, Diener\& Diener 1995). Psychological wellbeing inhabits within the experience of the individual (Campbell et.al, 1976).

Stanculescu (2014) examined psychological predictors and mediators of teacher's subjective well-being. The findings of his study enhanced the understanding of personal factors associated with teacher's subjective well-being. The constructs linked to subjective well-being promote school psychologists’ interventions for better school teaching performance.

Wangsoyoung (2014), in his study, investigated the relationships between self-differentiation, family origin, ego-resiliency, and psychological well-being among pre-service early childhood teachers. Regarding to the results of this study, the psychological well-being was significantly higher than the mean; but positively correlated with almost all aspect of self-differentiation.

Chan (2012) investigated the relationship between gratitude and forgiveness and psychological well-being among teachers. Regarding to the result of this study, gratitude and forgiveness correlated remarkably with each other as well as with meaningful-life orientation and psychological well-being.

Diener and et al. (1995) have also investigated the correlation between subjective well-being and the social, economic, and cultural characteristics of some nations. The subjective well-being surveys showed strong convergence, high income, individualism, human rights, and societal equality correlated strongly with subjective well-being across surveys. It has been noticed that income correlated with subjective well-being after basic need fulfillment has been controlled. Only individualism persistently correlated with subjective well-being when other predictors were controlled. However, Cultural homogeneity, income growth, and income comparison showed either low or inconsistent relations with subjective well-being.

In his study on women working in the paid work force, Erlandson (2006) found that those with low complex patterns of occupations improve their health and well-being better than women having medium complex patterns. Moreover, women with medium complex pattern take a turn for the better in health and well-being than women with high complex patterns. Regarding sociodemographic factors, the women in the three sub-groups differed in the level of education. On the one hand, full-time work mothers have positive tendency about service and better psychological well-being. On the other hand, better psychological well-being predictably assumed to bring about less behavioral problems and greater social competence. Besides, 


\section{The Relationship between, Psychological Well-Being and Occupational Self-Efficacy among Teachers in the City of Mysore, India}

psychological well-being of employed women is related to a balanced pattern of daily occupations and lifestyle factors.

Williams(2003) in his study among African-American professional women found that psychological well-being increase due to some major factors such as establishment of professional careers, achieving financial independence and the obtainment of coping resources.

Srimathi (2010), in her study on "Psychological Well-Being of Employed women Across Different Organization" (such as industries, hospitals, banks, educational institutions and in calling centers) concluded that female teachers have the highest level of psychological wellbeing.

Bandura (1977) described self-efficacy as opinions in one's capabilities to organize and apply the course of action required to manage prospective conditions. It means a decision about one's capability to fulfill a special behavioral template. For the establishment of and conversion in selfefficacy, belief system, four important originals have been determined. These originals are: mastery of experiences, vicarious experiences, social persuasion, and psychological responses to experiences. Faith in person's capability and policy to carry out and fulfill the duties at the occupational space define as occupational self-efficacy. It has a very well- fixed body of wisdom; having an applicability and established impact on task-linked proficiency. In his book "self-efficacy" Bandura presented a focused review on the growing research literature of the direct and indirect impact that self efficacy has on work-related personal and organizational effectiveness.

In (2012) Mudasir investigated the relation between occupational self-efficacy and the administrative behavior of educational administrators. The results of his study showed a significant positive correlation exists between occupational self-efficacy and administrative behavior of effective educational administrators. The results have also shown a low correlation exists between Occupational self-efficacy and administrative behavior of ineffective educational administrators.

Lin (2004) in his study claimed that progressing teaching efficacy gives teachers power to take determinations and obtain new insight to improve students’ learning outcomes.

Chu (2003) find out that teaching efficacy can promote students' learning motivation and prompt them improve their abilities. Gupta and Sawhney (2010) identified the interactive effects of gender differences on the perception of occupational self-efficacy and job type. The study concluded that females have higher confidence and personal effectiveness of occupational selfefficacy. 
Chaudhary et al. (2012), proposed occupational self-efficacy as the intervening variable between human resource development climate and work engagement. They found that self-efficacy mediates the climate-engagement relationship. The results support the moderating effects of selfefficacy on the relationship between climate and engagement. The relationship between climate and engagement is stronger for low self-efficacious individuals as compared to high selfefficacious ones.

Orput (1999) investigated the relationship between women's multiple role self-efficacy beliefs and career commitment. The results indicate that at a particular stage the combinations of career and family development moderate the relationship between multiple role self-efficacy beliefs and career commitment. In particular, level of multiple role self-efficacy beliefs was significantly predictive of level of career commitment.

Zhao (2012) investigated the intricate relationships among economic inequality, status perceptions, and subjective well-being. The result revealed that multiple indicators of economic well-being exert a significant effect on self-perceived social status and status change and on subjective well-being. Positive status perceptions, further, enhance better one's subjective wellbeing.

\section{Hypotheses}

1 There is a positive relationship between self-efficacy and psychological well-being among teachers in the city of Mysore, India.

2 The variable of gender has an effect on psychological well-being and occupational self efficacy among teachers in the city of Mysore, India.

\section{METHODOLOGY}

\section{Sample Selection and Description}

Using random sampling a total number of 600 teachers were selected from both government and private schools in the city of Mysore, India

\section{Tools}

\section{Occupational Self-Efficacy Questionnaire:}

The occupational self-efficacy questionnaire developed by Sanjoyot Pethe, Sushama Chaudhari and Pinder Dhar (2005) has been employed to assess the occupational effectiveness of the employees. The reliability coefficient of this scale is .98. Accordingly, the result of the scale indicated high validity as the coefficient rate achieved was 0.99 . The scale has the six sub-scales such as Confidence, Command, Adaptability, Personal effectiveness, Positive Attitude, and Individuality. 


\section{Psychological Well-being Scale Questionnaire:}

To measure Psychological well-being, Carol Ryff's Psychological Well-Being Scale (1989) was used. The responses to the questionnaire's statements have values rated from 1 to 6 ; for example, 1 indicates strong disagreement while 6 indicates strong agreement. Internal consistency values (coefficient Alfa) for each dimension varied between 0.86 and 0.91 ; which indicates high reliability of the scale. The Correlation coefficient with 20- item parent scale for each statement varies between 0.83 and 0.99 ; which indicates higher level of validity for the scale.

4. Gender: To identify the gender of the sample, the researcher has developed a personal data sheet; which includes some personal information such as gender, age, designation, sector, etc...

\section{DISCUSSION AND FINDINGS}

The first objective of the current research is to study the relationship between occupational selfefficacy and psychological well-being among teachers in the city of Mysore, India. Spearman's Correlation Coefficient has been applied by SPSS (version 20) to test the first hypothesis.

1. Hypothesis (1): There is positive relationship between self-efficacy and psychological wellbeing among teachers in the city of Mysore, India.

To find the relationship between psychological well-being and occupational self-efficacy, Spearman's rho Correlation Coefficient statistic test was used. The results are $r(598)=+0.367, \mathrm{p}$ $=0.00<0.05$; which indicate a significant positive relationship between occupational selfefficacy and psychological well-being.

The finding was supported by Maujean A. \& Davis P (2013) who have concluded that selfefficacy in psychosocial functioning was related to all components of well-being of stroke survivors, even when relevant demographic variables and level of physical functioning were controlled. Stroke survivors can continue to have considerable influence over their well-being and quality of life.

The findings of a study done by Natovová, L. \& Chýlová, H. (2014) also support the findings of the current study. They found that there are significant correlations between self-efficacy, behavioral markers connected to vulnerability to stress and well-being, in particular.

The second objective of this study was to investigate the effect of the variable of gender on psychological well-being and occupational self-efficacy among teachers.

\section{Hypothesis (2): The variable of gender has an effect on psychological well-being and occupational self-efficacy among teachers.}

Mann Whitney's U test was applied to check whether gender, males and females, has influence on psychological well-being. Mann-Whitney's U test results have shown no significant effect of gender on psychological well-being. The numerical results obtained from the application of Mann-Whitney's U test showed that the mean rank for females was 307.91while males had a 
mean rank of 285.69; the $U$ value obtained was 37038.000; and , finally, p value obtained was 0.139, ( $>0.05)$.

Mann Whitney's U test was also used to measure males and females influence on occupational self-efficacy. The results showed no significant effect of gender on psychological well-being. The numerical results obtained from the application of Mann-Whitney's U test showed that the mean rank for females was 295.25, 91; while males had a mean rank of 311.01; the U value obtained was 37898.000 and, finally, p value obtained was 0.297, ( $>0.05)$.

Roothman, B. and et al.(2003) studied the differences between men and women with regard to aspects of psychological well-being. The participants each completed 13 scales that measure psychological well-being in affective, physical, cognitive, spiritual, self and social aspects. They statistically found significant gender differences with small to medium practical effects. Men scored higher on physical self-concept, automatic thoughts (positive), constructive thinking, cognitive flexibility, total self-concept, and fortitude. Women scored higher on the expression of affect, somatic symptoms, and religious well-being. No significant gender differences were found on sense of coherence, satisfaction with life, affect balance, emotional intelligence, selfefficacy, and the social components of self-concept and of fortitude.

Huang, C. (2013) found that females have higher language arts self-efficacy than males who exhibited higher mathematics, computer, and social sciences self-efficacy. However, Sawari, S. \& Mansor, N. (2013) regarding the comparison level of general self-efficacy between male and female, they found that there are no significant differences for both gender. In additions, with regards to the correlations between general self -efficacy and gender, the study revealed that there is very weak correlation to negligible.

\section{CONCLUSIONS AND IMPLICATIONS}

Regarding to current study's results, occupational self-efficacy and psychological well-being have been found as a facilitator that affect teachers' performance in the educational field. However, the current study suggests that educational organizations should concentrate on some psychological aspects of teachers' personality, their occupational self-efficacy and psychological well-being. Giving a consideration to such psychological aspects will be helpful for better educational outcome. The finding of the study supported the evidence to focus on teachers' psychological aspects, reinforce them and encourage them as human resource trainers of society. In that case, both occupational self-efficacy and psychological well being can be mentioned as moderators in the educational organizations. 


\section{REFERENCES}

Bandura A. (1977) Self-efficacy: The exercise of control. New York: W. H. Freeman; 1997: 2-8.

Bandura, A. (1977) self-efficacy: Toward a unifying theory of behavioral change. Psychological review, 84(2), 191-215.

Campbell, A., Converse, S.E., \& Rodgers, W. L. (1976). The quality of American life. New York; Russell Sage foundation.

Chan, D.W. (2012),Subjective well being of Hong Kong Chinese teachers: The contribution of gratitude, forgiveness, and the orientations to happiness, Teaching and teacher Education, 3 (2),22-30

Chu, C. L. (2003). A study of the relationship between personality traits and teaching effectiveness of teachers in reward and non-reward kindergarten in Taiwan. Unpublished doctoral dissertation, Spalding University, Kentucky.

Diener, E. D., Diener, M.,\& Diener, C.(1995) Factors Predicting the Subjective Well-being of Nations. Journal of Personality and Social Psychology, 69(5), 851-864. http://dx.doi.org/10.1037/0022-3514.69.5.851

Erlandson (2006). Levels of complexity in patterns of daily occupations. Journal of Occupational Science,13, 27-36.

Huang, C. (2013), Gender Differences in Academic Self-efficacy: A meta- analysis, European Journal of Psychology of Education 28(1). DOI: 10.1007/s10212-011-0097-y

Lin, C. H. (2004). The study of organizational commitment and teaching effectiveness for special education teachers teaching. The Journal of Human Resource and Adult Learning, 9, (2), $141-153$

Maujean A, Davis P (2013) The Relationship between Self-Efficacy and Well-Being in Stroke Survivors. Int J Phys Med Rehabil 1:159. doi: 10.4172/2329-9096.1000159

Mudasir, B. (2012). Occupational Efficacy and Administrative Behavior-A study of Educational Educational Administrators in Kashmir. Research Scholar, 4(11), 30-37. URL http://www.sciencepub.net/researcher

Natovová, L. \& Chýlová, H. (2014), Is There A Relationship Between Self-Efficacy, Well-Being and Behavioral Markers in Managing Stress at University Students?, ERIES Journal .7 (1), $14-18$

Orput, D. G. (1999).The relationship between women's multiple role self-efficacy beliefs and career commitment using a stage analysis of career and family development. Dissertation Abstracts International: Section A. Humanities and Social Sciences, 60(2-A), 50-67.

Pethe. S. \& Caudhari.S. , Dhar, U. (2005), National Psychological Corporation, Agra.

Roothman, B, Kirsten, D, \& Wissing, M, (2003), Gender Differences in Aspects of psychological well-being, South African Journal of Psychology, 33 (4), 212-218.

Ryff, C. (1989). Scales of Psychological well being. Journal of personality and social psychology, 57, 1069-1081 
Ryff, C. D., \& Keyes, C. L. M. (1995). The structure of psychological well-being revisited. Journal of Personality and Social Psychology, 69, 719-727.

Salami, S. O. (2010).” Occupational Stress And Well-being: Emotional Intelligence, Selfefficacy, Coping, Negative Affectivity and Social Support as Moderators”, the Journal of International Social Research, 3,(12 ),387-397

Sawari, S. \& Mansor, N. (2013), A study of student's general self-efficacy related to gender differences, International Journal Of Informative and Futuristic Research, 1(4):2347-1697.

Srimathi, N.L \& Kumar, S. K. (2010). Psychological well-being of employed women across different organizations, Journal of the Indian Academy of Applied Psychology, .36, (.1), 89-95.

Stanculescu, E.(2014), psychological predictors and mediators of subjective well being in asample of Romanian teachers. Review of Research and social intervention,4(6),37-52

Wangsoyoung, H. (2014), A study of the relationships among pre-service early childhood teacher's self differentiation, family of origin, ego resiliency and subjective well being .Early Childhood Education research \&Review,18,(5), 503-525

Williams. K,. (2003), Has the Future of Marriage Arrived? A Contemporary Examination of Gender, Marriage, and Psychological Well-Being, International Journal of Development 12:35-55. 487.

Zhao. W. (2012), Economic inequality, status perceptions and subjective well being in China's transitional economy, research in social stratification ,30(4),433-450 . 